\title{
Globalization and the New Silky Road Project
}

\author{
Oleg N. Yanitsky \\ Doctor of Philosophy, Professor, Chief Researcher, \\ the Federal Center of Theoretical and Applied Sociology of the Russian academy of sciences.
}

\begin{abstract}
Modern globalization is realized not only in information-communication form embracing the planet. The article is aimed at the analysis of a 'linear' form of globalization implemented as a certain roads (ways, lines) crossing nation-states' borders and various natural, social and technical landscapes. The combination of ecological civilization concept and the New Silky Road advanced by the modern China's leaders is considered them as foundation of advanced model of globalization. A specificity of this ambitious global project, issues and prospects of its implementation, theory, method and database of its analysis, and new role of civil society organizations in this project analysis and realization are the main topics of the article. The author stressed a contradictory role of the sciences in such projects. On the one hand, the sciences have to assist to implementation of such projects. On the other hand, they have to reveal social and environmental risks accompanied the implementation process and minimized them. The author convinced that as the project will progress an amount and the strength of environmental and social consequences will grow. Besides, the author considers this project as a giant geopolitical enterprise with not yet well-developed theoretical-methodological apparatus and social technology of its implementation. A scenario of such long-term developmental project should be well elaborated and its movement should be well calculated including possible side-effects. Otherwise, such projects will transform into the ground for new geopolitical conflicts. In any case, an inter-disciplinary communication and political bargaining remains an urgent methodological issue and practical instrument.
\end{abstract}

Keywords: civil society, ecological civilization, linear globalization, linear cities, metabolism, mobility, the New Silky Road, the Rivers without boundaries Coalition, transboundary SBTsystem.

\section{INTRODUCTION}

In a set of previous articles I spoke about the sociobiotechnical systems (hereafter SBTsystems) as the integrities, contradictory but integrities, global, regional, national or local scale (Yanitsky 2016, 2017, 2018). But here we are dealing with another kind of integrity: linear or transboundary. Their distinguishing feature is that they are crossing any borders, political, social, technical or ecological. In other words, it's going on geopolitically and technicallyconstructed 'linear' SBT-systems the existence of which is a distinguishing feature of a new phase of globalization process.

Of course, such 'linear' systems had emerged long before like the Great Chinese Wall or the Stalin's Plan for Remaking Nature in the year of 1946. Recently, such defensive wall and other constructions exist in the US and Europe as a preventive measure against mass migrants' influx from Mexica or the Near East and Africa. But such buildings played mainly defensive role preventing particular state or civilization from foreign invasions or from negative climatic processes like dry wind or floods. 
In this article I intend to analyze an opposite case: devising and construction the SBT-system aimed at the pursuing geopolitical goals. Of course, the planned New Silky Road is a peaceful initiative. When it will be constructed, it will bring profit to all countries that this Road will cross. But it doesn't exclude the fact that the major beneficiary will be the China. It's easy to see from the fact that the China and not a consortium of neighboring countries has been the initiator of this giant transboundary project. Another indicator of contradictory nature of this project is various forms of disagreement and protests both from some state officials and civil society organizations.

\section{SPECIFICITY OF THE PROJECT}

The Project has a transboundary and cross-cultural character for several reasons. First of all it will be transnational project because the New Silky Road will cross several nation-states. There are examples of such projects. First of all it's the gas pipeline from the RF to the EU that crosses several nation-states. But this project had one-dimension character (gas supply) and had been coordinated by all countries involved. Nevertheless, such type of project cannot be everlasting and as one can see it is now under critics from several nation-states and their alliances. Then, the project under consideration will cross various types of natural, social and technical landscape and there need be no doubt that it will trigger substantial transformations in national economies, institutional and social structure and in culture and daily life of particular states and communities. After then, since this Project has geopolitical character it will generate a reaction of global and national stakeholders across the world and could generate similar projects in other parts of the world. An immediate response to such enterprise is already seen. But what will happen in the run of forthcoming decades? Finally, one should consider an implementation of the Project in a long-term perspective. In any case this Project will have a geopolitical feedback in many countries and countries' alliances. One thing is more or less clear: the construction an exploitation of such transboundary project has a sense in peaceful times only. Thai is, China strategically oriented on a lasting peace and cooperation between countries. But the one question is still exists: the coming Fourth Industrial Revolution may create new means not only of information but for a transportation of materials, goods and people.

\section{METHOD, THEORY AND EMPIRICAL DATABASE}

My methodological approach is based on the following points. First, following Russian (V. Vernadsky and A. Chizhevsky) and foreign (Forrester, 1969, 1971) theorists I consider modern world as tightly interrelated parts and subsystems. There is no separate nature, man and technological constructions. That is any dichotomy approach has already become obsolescent and should be replaced by integrative one. The global turnover of energy and matter (in any form) is combined with metabolic processes of various character, form and pace. To my mind, global-local metabolic processes are the major integrative force. That is my methodological approach is holistic one.

Thus, the following analysis is relied upon my concept of the abovementioned SBT-system. I consider the SBT-system of any scale as contradictory but integrative whole maintained by two kinds of metabolic processes: inside this particular system and its exchange with the outer world by means of metabolic processes of a greater scale. Of course, it's an ideal model only, an everyday life never fit to this model. On the contrary, an actual development of any SBT-system is possible only as a certain violation of such ideal model. Accordingly, any sustainable state or development of the SBT-system is no more than a moment in the process of its permanent transformations. 
The article is based on the analysis of Russian and foreign literature (see, for example, Dudley and Stolton 2012) and on the information collected several years by the Coalition of Rivers without the Boundaries and its experts and like-minders. The coalition is a cooperation of NGOs and experts from Mongolia, China, Russia and the US to work jointly in order to protect transboundary river system and to solve transboundary issues related to river ecosystem in North Asia. But to my mind, in the course of the activity of this Coalition their interests and tasks have been vided and qualitatively transformed. It was quite natural because the rivers are not only roads or sources of water supply. Recently even small rivers are inseparable part of the sub-continental SBT system under consideration. The size of this article doesn't allow me analyze a full volume of information gathered by the Coalition. I'll underscore only that it is the first case in my practice in which all related to the New Silky Road project had been so carefully collected and systematized.

Let me only to name main sections of the Coalition Database: participants, projects, multimedia, Asian rivers, etc. Then, the Database has 5 major thematic sections: current events, topics, details, the latest news and the Archives from January 2011 till March 2018. Besides this base have links to the most urgent events. Among the main topics ate adaptation to floods and climate change, river's basin management, civil society organizations, conferences, hydropower assessments, river energy, river activists, river-related risks, appeal to save Argun' river, and Sino-Russian hydro-power initiatives and projects.

\section{ROLE OF SCIENTIFIC RESEARCH IN MAKING GLOBAL PROJECTS}

Historically, such global projects had mainly been geopolitical ones guided by economic interests of a particular country and relied upon an ideology or belief, military force and technological innovations. Only after the WWII a world community began to realize that population growth, economic expansion and resources exploitation have the limits. And this realization gave a mighty impetus to scientific research of global scale, for making global legislation and to the development of new technologies. But up to now a struggle between scientific recommendations and the ideological postulates (like the Pax Americana that is the follower of Pax Britannica) is continued.

Recently, there are four mighty international groups (teams) that systematically study global processes and their dynamics. 50 years ago the Club of Rome was established under the motto the 'Limits to Growth' which produced about 40 various research reports (Von Weizsäcker and Wijkman 2018). Then it's a great international consortium of experts from about 200 countries guided by the World Economic Forum in Geneva. This consortium is aimed at the long-term study of global risks dynamics (see, for example, Global Risks report, 2016). After then it's an international team of about 20 countries guided by the group from the Alpen-Adria University in Vienna (Haberl et al., 2016). And the last but not least the Chinese global project titled the New Silky Road (variants the Belt Road Initiative and the One Belt One Road, see, for example, Tracy et al., 2017). In the last decade some international teams of the same character have emerged in the South Hemisphere. But only in the case of the New Silky Road we see international and well-organized civil society team which has its own view on this project (The Rivers without Boundaries, 2017).

It's interesting to compare the project of global risks research with the New Silky Road one. The former analyses global risks, their intersection and relative threat to humanity and global environment but without any correlation of the risks with a particular territory. The latter is a territorially-bind project but without any correlation with global state of affairs and with a reaction on this project the nation states, their population, business and other organizations and environmental conditions. The former is focused on global risks whereas the latter didn't 
take them into account at all. Thus, these two projects are mutually asymmetrical. If to continue such comparison, it appears that the Global risk research is based on massive expert surveys while the New Silky Road Project expresses the China's economic and geopolitical interests. These two global enterprises are adversarial ones in relation to global environmental issues. The former indicated the sources and the possible environmental risks on the crossroads of global networks while the latter announced a creation of 'green civilization' as an ultimate goal as a result of the abovementioned and other initiatives and projects.

\section{ON DISTINGUISHING FEATURES OF TRANSBOUNDARY SBT-SYSTEM}

First, such transboundary SBT-system is under force of a few global stakeholders only. In all other cases of long-term processes of the developing such SBT-systems, long-term talks and detailed agreements (protocols) are absolutely necessary. But it doesn't mean that already settled transboundary project will be constructed in time. As one can see, the gas pipeline titled the North Stream Two which is already under construction permanently undergoes critics and objections because such projects are always part and parcel of fluctuations of global market economy.

Second, it is clear that any transboundary system is an open one. As it will be planned and constructed new circumstances and impediments may emerge. This process is not equal to local 'developmental planning' that is more or less predictable one. On the contrary, the development of the transboundary SBT system will be full of impediments and unintended consequences because it is impossible to investigate and to predict all local and national peculiarities, circumstances and impediments. The matter is that such unintended consequences will emerge as the project will advance forward across the nation-states, social structures and environmental ecosystems.

Third, in the run of implementation of the above project a concern of local and regional business and authorities will grow. Is this process will be profitable for them or has negative consequences? The 20 year experience of building new infrastructural systems (gas-and-oil pipelines) showed that the firm which conducts such works prefers to use their national engineers and labor force, supervisors, guards, etc. than to hire the aborigines. Besides, it is clear that the construction of such mighty infrastructural project will generate a total reorganization of existing infrastructure and systems of town and other settlements. Russian history of XX century gives a lot of examples when a new railroad fully transformed a particular regional SBT-system.

Fourth, a transformation of natural and social ecosystems in the run of the Road construction is a separate problem for the same reason. This Road is not only the way but an infrastructural enterprise that will have many consequences in all spheres of industry including IT-industry as well as in natural and social environment. The particular specificity of this linear Road project is that some rivers (Amur and some others) which Russians are accustomed to count as the 'ours', are indeed a common good of the RF and China. And the key for Amur regulation is in China and not in Russia. And any changes in regime of Amur regulation will have numerous immediate and postponed consequences for natural landscape and human beings. That is such shifts will change various metabolic processes, etc.

Fifth, the above issues pose the next question: How such transboundary projects interrelate with the system of international laws? It's a key question because such global transboundary projects as the New Silky Road has a risk to be converted into self-sustained system that is in a kind of the state within a set of nation-states. Consequently, the key issue here is who will be a manager of the above project, and the constructor and regulator of its logistics, because in the 
final analysis the logistics of this Road is a heart of this overall enterprise. In addition, a lot of issues will emerge: relationships between the New Silky Road and national taxes, customshouses, safety supply, repairing teams, etc.

Sixth, the very idea of building of such transboundary Road gave a mighty impetus for an activity of civil society organizations of the region. This topic is the most close to me because I spent a large part of my professional life for the study of grassroots and environmental and other social movements (see, for example, Yanitsky 2012). The matter is acute at least for two reasons. First, it will revitalize environmental movement in the region, the Russian one as well as in the Asian countries of the former Soviet Union, and second it poses a new kind of issues before them. To my mind, Russian environmentalists as well as their allies in the former Soviet Union never dealt with the issues of global scale. Besides, this transboundary project will revitalize the close professional-and-social ties between Russian and Mid-Asian environmentalists.

Seventh, to my mind, a scientific community never dealt with an object of such scale and complexity. A distinguishing feature of the Road project is its developmental character. The scientists and scholars are usually dealt with 'organisms,' be it a man, a community, a city, a region or the globe as a whole. Paradoxically but it's the fact: our world is permanently transforming but the researchers prefer to study stable objects (maybe there is a root of their inclination to sustainable development concept?). The Road project and its dynamics is one more impetus to the researchers to shift a focus of their interest from stable objects to movable ones. Such shift means a necessity to develop new instruments for field-research.

Eighth, the emergence of such extremely complex and developing object is beyond the capacity of comprehension of mass-media. The media prefer one-moment events (the breaking news) but their analytical potential is rather restricted. Besides, the media try to avoid tricky political events with unknown outcome. The regularities of tempo-rhythms of non-linear processes are not their theme. The media coupled with the advertising pressure make human perception of external reality collage-like. That is why the population of human settlements near the New Silky Road trace is mainly indifferent to this matter.

Ninth, to sum up the projects like the New Silky Road is a qualitatively new form of current globalization, the linear one. It is needed in new forms of cooperation between politicians, businessmen, scholars and scientists. Such cooperation has to be permanent and multisided. The issues like this project cannot be resolved only by top managers of each country one by one. A new level of cooperation between geopolitics, scientists, scholars and civil society organization is needed.

Tenth, the Russian's government attitude towards the Road project is still not clear. Even in the year of 2013 the Chinese authorities officially announced new strategy of economic development. Titled as the 'One belt-One Road', it was aimed in particular at the construction of an infrastructure of various ties within Eurasia continent: communication, information, transportation, etc. But Russia is still not among official participants or stakeholders of that Project and program of economic development. Russian authorities took the position of waiting. Russian experts called this stand as the political but not the economic one. This stand was conditioned by divergence between the positions of Chinese and Russian authorities: the Chinese is interested in the road for transportation and sale Chinese goods while Russians are interested in new investments in its economics. Local population is needed in any work, qualified or unqualified. The sources in civil society organizations draw attention to legal and illegal penetration of small Chinese organizations into Russian territory. 
Finally, in the Report on the Development of the Hydropower and the Hydro-economic Infrastructure in the North Eurasia and Globally (Simonov et al. 2018), the members of the RwB Coalition refer to the UN General Secretary appeal to recognize the nature's right for existence (compare with human rights) and a necessity to the transfer to earth-centered global legislation. If this right will not be recognized we will see new kind of social conflict: between hydropower developers and users and local population. The reason is rather simple: a rapidly growing deficit of drinking water and water for hunting and agriculture.

\section{REVITALIZATION OF THE IDEA OF GREEN LINEAR CITIES?}

In the 1920s, the projects of such cities were designed by Russian des-urbanists. It hadn't been only particular projects but conceptual works related to the near future of Soviet cities generated by the coming forced Industrial revolution. Soviet urban planner and sociologist M. Ocihtovich had been the main ideologist of des-urbanization. This idea came out not from nowhere. The matter is that along with rapidly develop network of railroads in tsarists Russia a set of small towns and settlements had been built. These cities designed and built by professional engineers and populated by engineers and high-skilled workers were true green cities. Some of such green towns still exists as a system 'one enterprise-one settlement' (in Russian monogorod).

The need for designing of linear cities in the 1930s had been conditioned by several reasons: a huge dimension of the country; a historically-shaped 'linear habitats' composed from small settlements along with railroads; and by the reason that the mega-cities inherited from the past were overpopulated. In order to fasten the construction of new enterprises Ochitovich also offered to create mobile towns like in the US. Besides, the des-urbanists considered the linear cities as a mean for making them 'green.' It's indicative that in the 1960s such small towns were considered as a measure diminishing negative consequences of possible nuclear strike (more details see in: Khazanova 1980; Meerovich 2012). If the Project of the New Silky Road will be realized it undoubtedly revitalize the idea of linear towns along this road in various forms.

\section{ON EVOLUTION AND PROSPECTS OF THIS PROJECT}

It is the most difficult and disputable part of the article. I'm forced to start from the mentioning that regularities and trends of any global or sub-continental SBT-system have to be taken into account.

First, the abovementioned project is only one among other projects. Now it's only the project and not a functioning SBT-system and nobody knows in what terms and forms it will be implemented and what will be it consequences.

Second, basing on the SBT-concept I may state that the Project being inserted into the subcontinental i.e. the North Asian context will be necessarily substantially changed or even transformed. Working as urban planner for decades I never see the project which has not been transformed in the process of its implementation. The further the Road project will be realized the more impediments and obstacles it will meet.

Third, the authors of any project usually forget that an environment in which it will be implemented is never passive because it's an actor as well. And the Coalition RwB members well understand it if they pay so much attention to natural, social and technical environment within which this Project to be implemented. 
Fourth, relying on works of great western theorists of globalization and its risky consequences (Z. Bauman, U. Beck, M. Castells and J. Urry) I insist that the project as single-moment decision fixed on paper means nothing! Irrespectively, be it individual or collective decision, fixed as a master-plan or electronically, etc. Permanently moving reality is needed in 'movable projects' that is in in a set of scenarios of object-environment evolution. Of course, the character of such movement may be different, from more or less coordinated to contradictory and even mutual annihilation.

Fifth, earlier I talked about metabolic processes. But now when these evolutionary-shaped processes may be stopped, destroyed or fastened the situation is qualitatively changed. Now at the very beginning of the project we may speculate about possible scenarios of its development only.

Sixth, one must keep in mind that the above project is not ordinary. On the contrary, It's a project aimed at geopolitical domination on the North Asia subcontinent and not only on the land but on the sea as well. The point of the matter is how this domination will be used?

Seventh, it in turn raises the following question: Is this project only economic as it had been officially stated or it is a civilizational breakthrough?

Eighth, what will be reaction to this project from India, on the one hand, and the US, on the other hand? Objectively, China and India are two superpowers on this subcontinent and therefore a conflict between them is possible but in what form and with what tempo-rhythm? And what will be the role of the RF, Kazakhstan and other neighboring countries in this case? The most interesting question in this crossroad of geopolitical interests is the US position in relation to this project. The US and China are already competing on this subcontinent and neighboring ocean and seas. In my view, the US government makes stake on India, or maybe on China? Does it mean that the relationships of these two global giants worsened?

Tenth, what are the Russian interests in this region? It's clear that Russian geopolitical principle to maintain good relationships with all parties involved. Does the RF position in relation to the New Silky Road project will remain unchangeable? And how Russian authorities will respond to the concerns of majority of civil society organizations in relation to the rivers without borders issue?

\section{THE ROLE AND TRANSFORMATIONS OF CIVIL SOCIETY ORGANIZATIONS}

I'm capable to speak mainly about Russian environmentalists that had been the subject matter of my studies in the run of about last 40 years. To my mind, the shifts happened in the run of the last 20 years were rather substantial.

First, any political divisions on the 'lefts' and 'rights' has gone. The divisions on nature defenders, traditionalists, alternativists, anarchists, socialists and technocrats are now not exist at all (Yanitsky 1996). True environmental NGOs or their activists are not in the state and regional power structures. There are only some of them in municipal bodies. The protests are usually the only one form of their participation in local political process.

Second, nevertheless in the course of the above two decades a social potential of Russian environmentalists has grown very seriously. Their training by the everyday life was their main teacher and tutor. This education process has two sides: an inclusion in global and local information-communication networks and direct participation in various actions ranging from compiling petitions and demands to participation in direct but peaceful actions. In sum, a 
majority of modern Russian civil activists are not only well-educated but they become highly experienced people. And it's a very important social transformation of civil society in our times.

Third and directly related to the theme of this article, it's the turn to local-global mode of thinking and activity. It was not a result of academic education but an outcome of everyday presence in global networks coupled with personal experience of civic activists. We sometimes exaggerate the role of a classroom teaching. Neither secondary school nor higher education institutions are capable to go hand-in-hand with permanently increasing speed of global-local events and transformations. Of course, I'm not against the education but it must be developmental as well.

Fourth, as everyone can see, global processes exist not only as information-communication flows which could be switched off but as direct impact on people, nature and technical constructions. If the project begins to implement it immediately encounter with numerous social, natural and technical issues both in situ and everywhere. As analysis of the RwB Coalition activity shows, it has been immediately involved in this process.

Fifth, such involvement requires an interdisciplinary knowledge and multisided professional and public activity. This activity is beyond the capacity of grassroots - a combination of interdisciplinary knowledge in many realms of metabolic processes with a potential for public activity, especially if it's going on about such critical events as forest fires, tornados and folds.

Sixth, the reverse side of the same coin is the compiling an archive of the RwB Coalition activity and its allies and adversaries. The archive-making has two interrelated sides. On the one hand, it allows to the Coalition members to trace their own activity and therefore not to repeat the past mistakes. On the other hand, such archive is a good instrument for the Coalition's public activity and dissemination of its results.

Seventh, a network structure of the above Coalition with other organizations or institutions is very important as well. This structure allows to detect timely a disposition of main forces and to reveal of the Coalition like-minders, supporters, bystanders and adversaries. Under conditions of permanent movement ahead of the Road project the new obstacles or unintended consequences will emerge, and it's very important to trace a feedback of the above disposition. Eights, the environmentalists (as usual) play the role of the voice of natural ecosystems because all other stakeholders though being more or less concerned with environmental issues nevertheless pursue other aims, first of all geopolitical and economical. It means that the true environmentalists have to be politicians which first of all concerned with the state of natural and social environment. Besides, it signifies that these activists have to keep distance from all other stakeholders.

Ninth, it's a rule that the corps of environmentalists is permanently transforming. But my observations on this process showed that the key figures (the leaders) of environmental organizations are on the same places. It doesn't mean that they have become the conservators or bureaucrats though such metamorphoses may happen. But in an overwhelming majority of cases it means that the members of such corps found a certain balance in their professional or public carrier.

Tenth, two forms of civil society organizations' activity is the most important: the revitalization of public hearings with participation of business and regional authorities' representatives and collaboration with bank system (Simonov et al. 2018). The RwB Coalition is not a single defender of rivers. There is one more similar organization called 'Not to the Dams' situated in 
the midst of Siberia that also struggle in defense of the North Eurasia rivers. The both civil organizations act under the motto 'the Rivers are the Source of Life and not of an Electricity' underlining their environmental value. These organizations come out in favor of gradual cutting down the hydropower stations and a revitalization of natural regime of rivers and their ecosystems.

All said above means that the civic activists brings to light the 'hot spots' in the sphere of their concern and therefore makes these 'spots' public for scientific discussions and decisionmaking. A global scale of that activism allows to the activists to compile global picture with local issues of the sphere of their concern. Then, the activists together with scientists-turnedcivil activists are becoming capable to estimate the degree of risky situations emergence and to inform the nation-states and their population of possible accidents and social consequences. After then, by and large the work of such Coalitions becoming more and more public allows to form global Rivers without Boundaries union or another form of amalgamation. Their capacity to interrelate the rivers issues with all other ones means that such coalitions are working in the SBT-format.

\section{CONCLUSION}

The planet-centered approach is of course welcomed. But our planet is not only a creature of the Nature. Today, our planet is a complex organism with natural, social and technical systems of adversarial character. Therefore, the maintenance of planet-centered approach means the building not a contradictory model of the relationships of above three interrelated subsystems. Besides, we are dealing here with another type of globalization process and its structuralfunctional organization. A technologically-constructed 'linear' SBT-system is a new form of current globalization. Its complex essence remains the same but spatial form and temporhythms of its practical realization are the others. For the reason that it is the globalization-onearth project an amount and character of its side-effects would multiplied. As the New Silky Road progresses, new forms of its interplay with local and regional environments will emerge. In turn, it means the emergence of new metabolic chains and transformations with unknown side-effects including social and cultural transformations.

A united project of the New Silky Road presupposes one (leading) developer. In the case under consideration there will be many the stakeholders and groups of interest. How they will interrelate with each other and with natural, social and cultural environment is still an open question. Anyhow, the New Silky Road project confirms the principle of close interconnection between a theory of globalization, methods of developmental planning, a scenario methodology and new methods of monitoring. To my mind, it should be two-sided monitoring: on the advancement of the project as such and on the consequences which it will produce.

The project under consideration gave new impetus to a development of civil society organizations in situ and everywhere. But how their modest capacities will influence the interplay of mighty global stakeholders and nation-states is still unclear. To my mind, there is only one way to surmount this gap: to coordinate their activity both with other NGOs across the world and with global institutions responsible for the maintenance of human rights and for conservation of natural ecosystems. In the run of their activity the Coalition members and its allies learn to think glocally and in interdisciplinary manner. And the fact that the authors of the Report (Simonov et al. 2018) don't mention my SBT-concept means nothing. On the contrary, I'm very happy that these authors empirically came to the same idea that I've done theoretically. 
Thus, there are two main forms of globalization process. A 'direct' implemented by means of linear technical infrastructures (airlines, pipelines, auto and railroads) that in one way or another destroyed an environment. And an 'indirect' realized by means of the informationcommunication systems. For the first glance, it seems that the second is less risky than the first. But the construction of artificial intellect and other unseen but potentially risky technological inventions of global scale refute this suggestion. In the final analysis a man by means of new technologies step by step restructures a total environment of his existence. An issue of the limits of growth remains acute, but the further the more not in the terms of quantitative growth but in the terms of qualitative transformations.

In spite of the above and many other difficulties and uncertainties I consider the New Silky Road project as new form of globalization process which clearly shows that modern globalization cannot be reduced to its information-communication form only. But in comparison with its network-like forms the 'linear' model i.e. the globalization-on-the earth is now potentially much more risky than in its other forms.

The combination of a new ecological civilization concept and the New Silky Road advanced by the China's leaders is rather interesting but it's needed in a more detailed interdisciplinary and geopolitical substantiation. The projects like the New Silky Road should serve not only to peace and wellbeing of the countries involved but to humanity as a whole and to revitalization of natural ecosystems.

The above analysis of a set of global projects is a necessary theoretical-methodological ground for the development similar projects in Russia or/and globally. As one can see, the strategy, tactics and necessary intellectual and financial resources for the development of the above projects is still a 'black box.' If it will be not done in time, it will be a new source for tough geopolitical conflicts and endless bargaining.

The reverse side of the same coin is an interdisciplinary research. The majority of globalization researchers are in favor of inter/trans-disciplinary investigations but still nobody offers the method of translation from one scientific language to another one. And about of construction of a certain unified vocabulary is no one word. Taking into account the difficulty of the abovementioned problems and its developmental character the future of existing institutional structure of the science have to be reconsidered.

\section{FUNDING}

The research was supported by Russian Fundamental Research Fund under grant 'Russian megacities in the context of new social and environmental challenges: building complex interdisciplinary model of an assessment of "green" cities and strategies for their development in Russia', project No 17-78-20106.

\section{References}

Dudley N. and Stolton S. 2012. To Dig or Not to Dig? Criteria for Determining the Suitability or Acceptability of Mineral Exploration, Extraction and Transport from Ecological and Social Perspectives. WWF Discussion Paper, OECD Global Forum for International Investment. Available at: https://www.oecd.org/env/1830332.pdf

Haberl H., Fisher-Kowalski M., Krausmann F. and Winiwater V., eds. 2016. Society-Nature Relations across Time and Space. ISBN (on-line): 978-3-319-33326-7. Available at: http://link.springer.com/book/10.1007\%2F978-3319-33326-7

Khazanova V. 1980. Soviet Architecture of the Years of the First Five-Year Plan: The Problem of a Future City. Moscow: Nauka (in Russ.). 
Meerovich M. 2012. Urbanism or Des-urbanism? Discussion on the Future of the Soviet Cities (in Russ.). Architecton: Izvestiya Vuzov, no 37, March. Available at: http://archvuz.ru/2012 1/13

The Global Risks Report 2016. Geneva: World Economic Forum. Available at: www.weforum.org/risks

The Rivers without Boundaries. Available at: http://www.transrivers.org/topic/civil-society

Tracy E., Shvats E., Simonov E., Babenko N. 2017. China's New Eurasian Ambitions: the Environmental Risks of Silk Road Economic Belt. Eurasian Geography and Economics, 58:1, 56-88.

Available at:http://dx.doi.org/1080/15387216.2017.1295876

Simonov E., Zabelin S., Kotov A., eds. 2018. Development of the Hydropower and the Hydro-economic Infrastructure in the North Eurasia and Globally. The Report prepared by the Rivers without Borders Coalition (mimeo, in Russ.).

Simonov E., Zabelin S., Kotov A. 2018a. The North Eurasia-2017. Rivers and Lakes: the Treats and Protection from them. Brief Report of the Rivers without Boundaries Coalition (mimeo, in Russ.).

Von Weizsäcker E.U. and Wijkman A. 2018. Come On! Capitalism, Short-termism, Population, and the Destruction of the Planet. Springer. DOI 10.1007/978-1-4939-7419-1

Yanitsky, 0. 2012. From Nature Protection to Politics: The Russian Environmental Movement 1960-2010. Environmental Politics. 21 (6): 922-940.

Yanitsky 0. 2016. Sotsiobiotechnicheskie systemy: novyi vzgliyad na vzaimodeistvie cheloveka i prirody [Sociobiotechnical systems: New View on Man-Nature Relationships, in Sotsiologicheskaya nauka i sotsial'naya praktika, Vol. 4, no 3: 5-22 (in Russ.). Available at: http://manuscript.sciknow.org/uploads/ojssr/pub/ojssr_140963345.pdf

Yanitsky O.N. 2017. On Transition from the Second Industrial Revolution to the Fourth one. International Journal of Media, Journalism and Mass Communication. Vol. 3(2): 1-10. Available at: http://www.arcjournals.org/pdfs/ijmjmc/v3-i2/1.pdf

Yanitsky 0.N. 2018. Global Risk Networks: A new Field of Interdisciplinary Studies. International Journal of Research in Sociology and Anthropology. Vol. 1 (1): 8-15. Available at: https://www.researctgate.net/publication/323657525 